\title{
COMMON CYCLES AND BALTIC-NORDIC ECONOMIC INTEGRATION
}

\author{
Scott William HEGERTY \\ Northeastern Illinois University, USA \\ Corresponding author e-mail: S-Hegerty@neiu.edu
}

\begin{abstract}
For centuries, Estonia, Latvia, and Lithuania have enjoyed historic and economic ties with their Nordic neighbors in the Baltic Sea region. While the period since 1991 has been one of increased integration with the European Union, trade linkages with Finland and Sweden are particularly strong for Estonia and Latvia, respectively. This study addresses these connections by applying time-series econometric techniques, with the goal of highlighting where regional connections are strongest. Strong Nordic-Baltic linkages, while providing evidence that historical factors are still important, might also suggest that integration with the rest of the EU is relatively weak. Using quarterly data from 1994 to 2014 for Baltic, Nordic, and other partner countries, business cycles are modeled for output, consumption, and investment. Common regional cycles are also extracted via Principal Components Analysis for the three Baltic countries and for the Nordic countries of Denmark, Finland, Norway, and Sweden. Cross-correlation functions are then generated for various cycle pairs to assess whether any are "synchronized." One key finding is that the Nordic region has two possible consumption cycles that behave in very different ways, suggesting that this region does not behave as a coherent whole. Norway and Denmark drive one cycle, while Sweden and Finland drive the other. Another key result is that each Baltic country behaves differently from one another. While regional differences are quite large - making it harder to describe this as a single "region" at all - Estonia does show significant connections to Finland, its historic and linguistic neighbor.
\end{abstract}

Keywords: Baltic region, common cycles, Nordic region, principal components, Synchronization.

JEL Classification: E32, F32.

\section{INTRODUCTION}

Since at least the 12th century, Estonia, Latvia, and Lithuania have shared trade networks, a common history, and linguistic ties with their Nordic neighbors to the north. Through centuries in the center of various imperial struggles, and even during the 20th century, the Baltics' ties with the Nordic region have remained strong. Estonia, in particular, with a related language and a common heritage, continues to enjoy strong economic linkages with Finland. Today, as the combined region deepens economic, political, and defense ties, the future of the Nordic and Baltic economic region is of particular importance. Its cohesion, measured as the strength of economic comovements, might help determine the future of Northern Europe. 
For this reason, it is crucial to understand the regional and sub-regional linkages that can help augment - or, on the contrary, destabilize - the European Union as a whole. If Baltic-Nordic connections are relatively stronger than other subregional linkages, for example, it might suggest that the European Union as whole might suffer from a lack of cohesion that might impede unified economic policies. More positively, such linkages might inspire policymakers to treat this seven-country subregion more as a unified economic space. Proponents of wider integration would therefore be advised to examine the Baltic-Nordic region to address where integration is strongest, while historians and those in other disciplines might be able to evaluate the continuation of long-held ties among the nations of the Baltic Sea Region.

This study uses time-series data to examine business cycles in the three Baltic countries, as well as in four Nordic countries and three major economic powers. Using the Hodrick-Prescott (1997) Filter, we extract common business cycles for output and some of its components. We then apply Principal Components Analysis (PCA) to extract common cycles that capture the series' shared variance. We then compare linkages between individual countries and these common cycles. Overall, we find evidence of Baltic common output and consumption cycles, with less support for a single Nordic consumption cycle. Linkages between the Baltic countries and these cycles, for various GDP components, differ widely. This can be attributed in part to differences in each nation's history and role in the region.

A number of studies in the literature that examine business-cycle comovements and their underlying determinants were conducted before the 2008 global financial crisis. In addition, a large share of the relevant literature excludes Central and Eastern Europe (CEE), while focusing primarily on Western Europe. Those studies that examine CEE countries sometimes exclude the Baltics. Artis et al. (2008), for example, include only Estonia among five other Central European countries over the period from 1995 to 2004, calculating contemporaneous correlations among business cycles. After the 2004 accession of 10 CEE countries to the European Union, however, interest in the area increased. Fadejeva \& Melihovs (2008) find evidence of a common factor for Baltic and European growth rates. Darvas \& Szapáry (2008) capture a common factor in the region's business cycles and calculate correlations, but find little synchronization between the Baltic group and Western Europe. Hegerty (2010) finds strong evidence of a Baltic economic region, using data that end in early 2008. Later studies, including Jiménez-Rodríguez et al. (2013), Aastveit et al. (2016), and Di Giorgio (2016) also examine various Nordic and/or Baltic nations, oftentimes applying more advanced methods. While the earlier studies often arrive at mixed results, we expect that additional years' worth of data, including the pre- and post-crisis periods, will help us examine the future of the region.

\section{METHODOLOGY}

This study extracts business cycles using time series data using the HodrickPrescott (H-P) filter, which was introduced by Backus et al. (1994). Quarterly GDP data are taken from the International Financial Statistics of the International 
Monetary Fund, from the period from 1995 to 2014. A total of 10 countries (listed below) are studied, with output and consumption analyzed for all countries, and investment also examined for the three Baltic nations. Real variables are constructed from nominal ones using the GDP deflator, Consumer Price Index, and Producer Price index, respectively. After deseasonalizing the data (using the Census-X12 method) and transforming them into natural logs, we then apply the HP filter (lambda $=14400)$ for each individual cycle to extract output, consumption, or investment series. We then note any relevant patterns in each series.

Next, we apply PCA, which extracts the common variance from multiple series, to the three Baltic and four Nordic countries. Following standard procedure, we examine only those components with eigenvalues above one. We then plot and examine each common series, and note those cases where there are multiple series.

Finally, we calculate cross-correlation functions, which capture relationships between one series in a given quarter and the other series up to four quarters in the present or future. Here, $k$ ranges from -4 to +4 , with $k=0$ representing contemporaneous correlation, and the other values represent one series "leading" or "lagging" the other.

$$
\rho_{t+k}=\frac{\sum\left(X_{t}-\bar{X}\right)\left(Y_{t+k}-\bar{Y}\right)}{\sqrt{\sum\left(X_{t}-\bar{X}\right)^{2} \sum\left(Y_{t+k}-\bar{Y}\right)^{2}}}
$$

If a pair is "synchronized," the highest correlation value will be found at the same point in time for the two series (having a lag or lead of zero). If the highest value is found between one series' present value and another's past or future value, we can say that one series "lags" or "leads" the other. It is also possible that low correlation values might indicate no connection between the two macroeconomic cycles in each pair. Examining these results allows us to assess the strength of interrelationships among Baltic, Nordic, and partner cycles.

\section{RESULTS}

Individual Baltic output and consumption cycles are presented in Fig. 1. We see the effects of the pre-2008 "boom," in which excessive capital inflows led to inflationary pressures, followed by the crash. We see similar movements among the Nordic cycles, which are depicted in Fig. 2. Unlike the Baltic cycles, however, these cycles exhibit major differences. This is particularly true for the Nordic consumption series. Finland, in particular, seems to move countercyclically to the other series.

We also present our PCA results in Table 1 (located at the end of this paper). Important to note is the fact that all groups have one common cycle except Nordic consumption, which has two principal components with eigenvalues greater than one. This confirms our suspicions that the Nordic countries do not form a single economic space. In fact, while the factor loadings for the Baltic principal 


\section{Output}

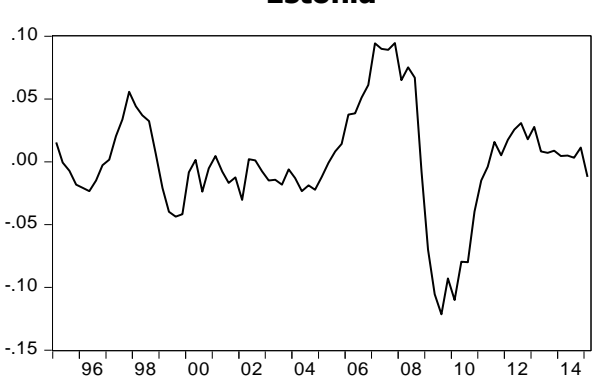

Lithuania

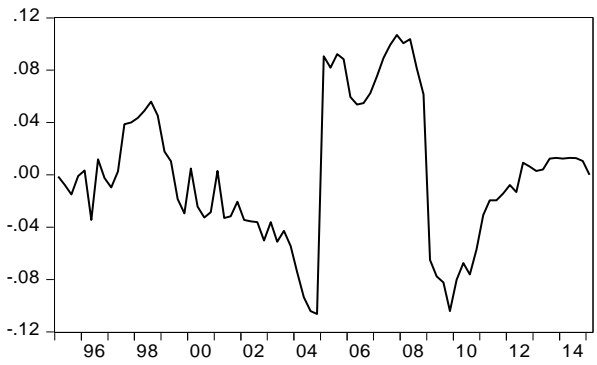

Consumption

Estonia

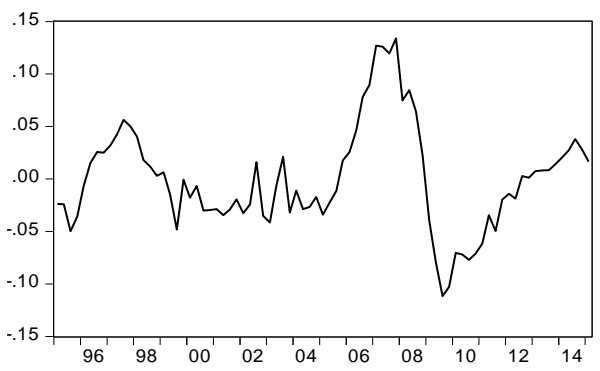

Lithuania

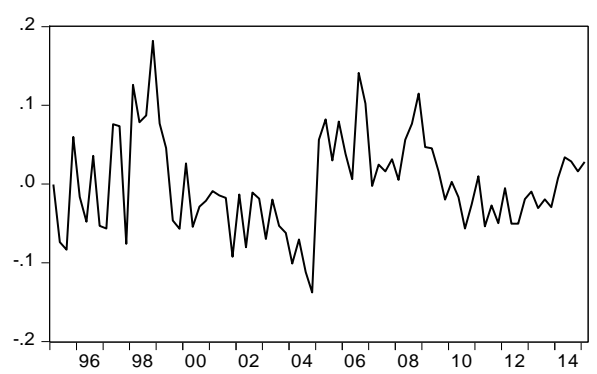

Latvia

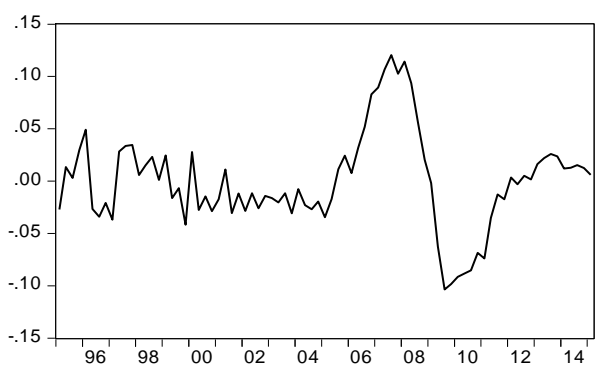

Baltic

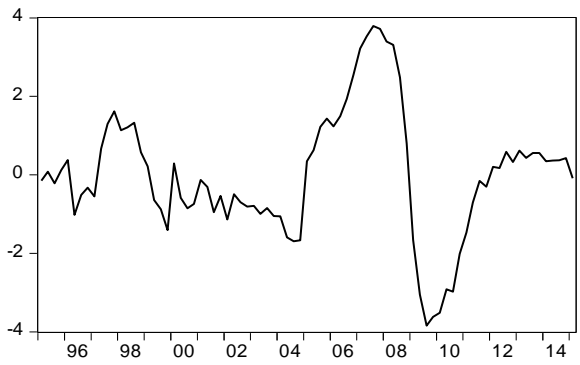

Latvia

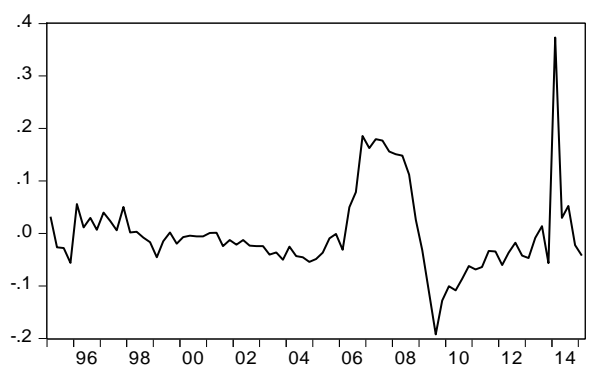

Baltic

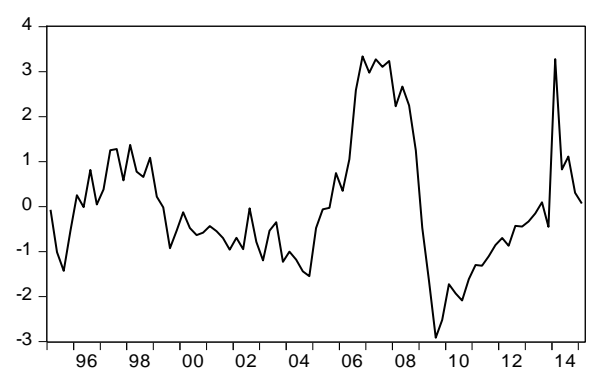

Fig. 1. Baltic output and consumption cycles, quarterly, 1995-2015 (International Monetary Fund, calculations by the author).

Components are fairly equal in size for all three countries (with the exception of the small value for Lithuania in common consumption), Norway and Denmark contribute heavily to one Nordic consumption cycle, and Finland and Sweden contribute to the other. Likewise, Norway plays a relatively small role in determining the common Nordic output cycle. 

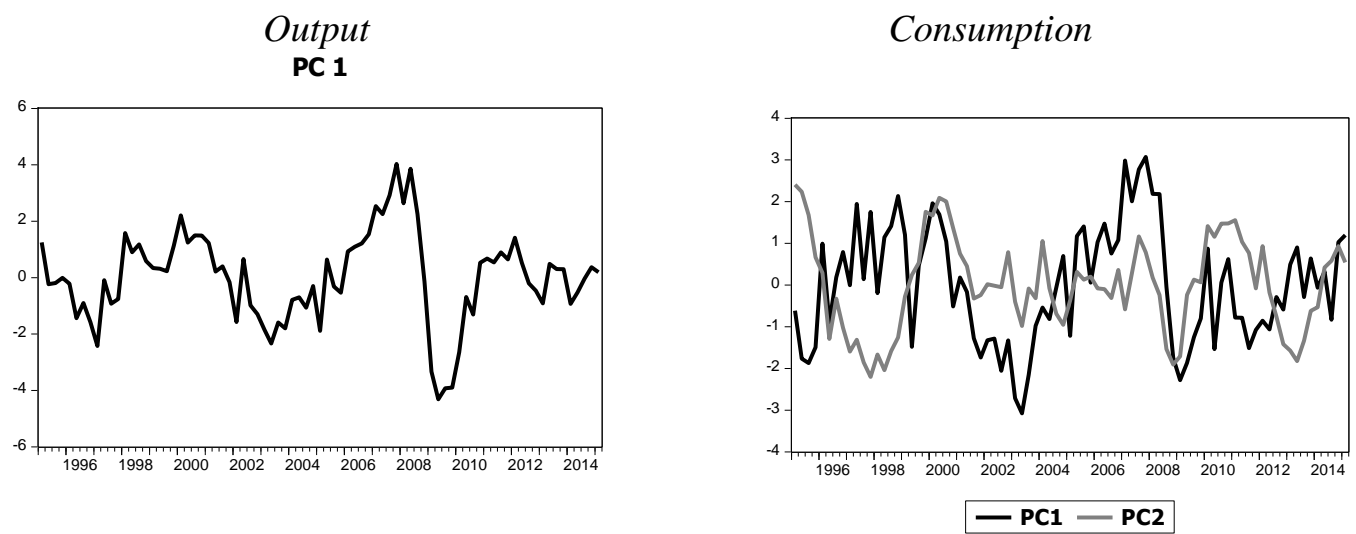

Fig. 2. Nordic output and consumption common cycles.

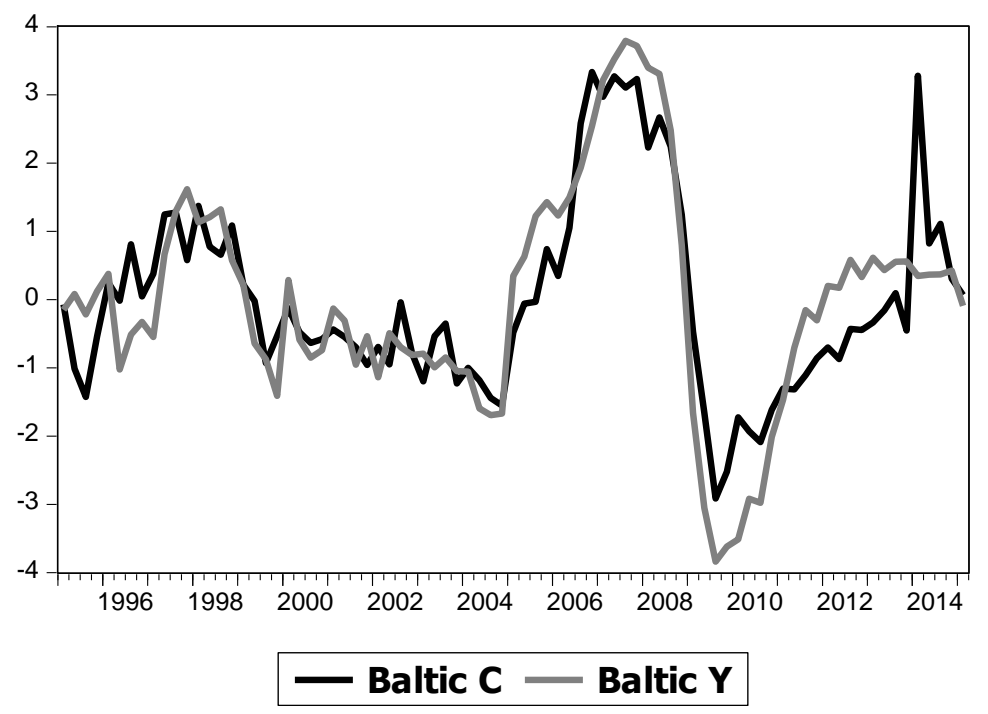

Fig. 3. Baltic output and consumption common cycles.

The common Baltic cycles are depicted in Figs 1 and 3, and the common Nordic cycles are in Fig. 2. While the two Baltic cycles are clearly highly correlated, the two Nordic consumption cycles are out of sync. As such, we conclude that there really is no such thing as a "Nordic" economic region, while the Baltics do indeed form an integrated space. While religious and other differences make each Baltic country unique, they share more economic characteristics than critics often admit.

The output and consumption cycles of three major partners are depicted in Fig. 4. Output generally moves in the same direction for each country - with the exception of Russia during the 1998 crisis - and Russia has larger consumption swings. As such, we confirm our suspicions that Russia is the true "outlier" among all the economies studied here, and that the Baltic and Nordic economies are more likely to be synchronized with their Western neighbors. We expect each Baltic country to exhibit different degrees of interconnection among each partner, however. 


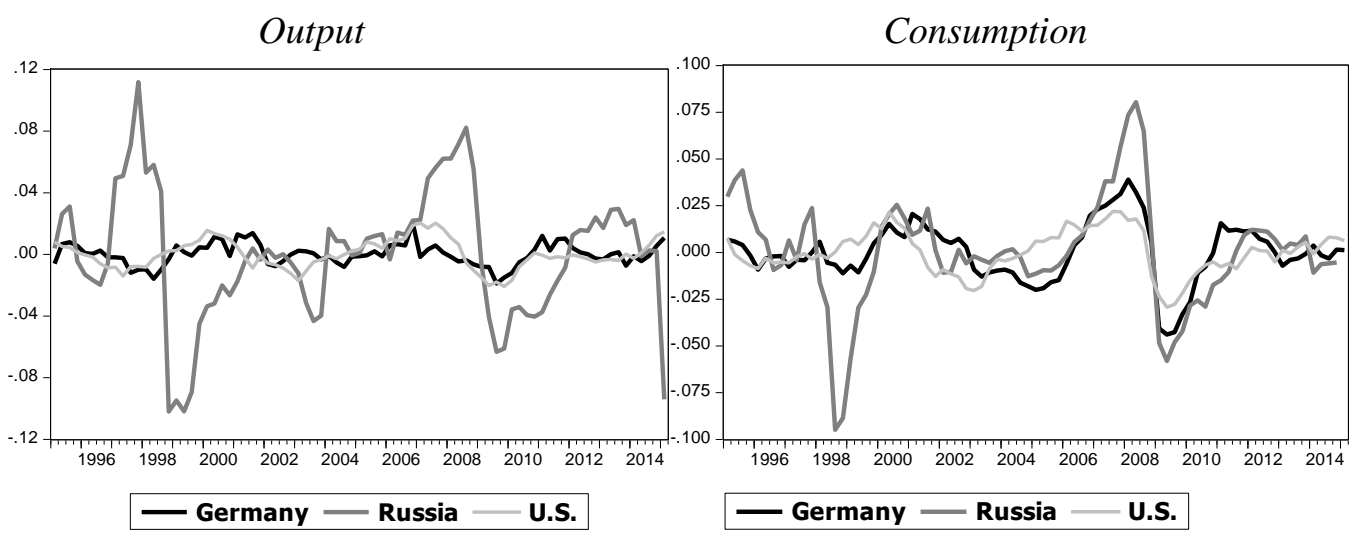

Fig. 4. Partner output and consumption cycles.

Finally, we calculate cross-correlations for all three Baltic nations' output, consumption, and investment series, which allow us to evaluate our key question: Which subregions have the strongest linkages? These results, with their standard errors, are presented in Table 2. We focus on those correlations that are strongest, noting that high correlations at zero lags represent business-cycle synchronization.

In particular, we note that Estonian output is more synchronized with partner output than is consumption, while investment is hardly correlated with partner GDP at all. Almost all of the Estonian output correlations are highest at zero lags, implying synchronization, and the correlation values are high. Estonia's highest output correlation (0.771) is versus Finland, which drives the high correlation (0.744) with the Nordic output cycle. This is higher than the correlation with German and Russian output (0.726 and 0.585, respectively); the U.S. output value of 0.676 is not synchronized. Estonia's only other evidence of consumption synchronization is vis-à-vis Russia (with a relatively low value of 0.489). Most likely this lack of correlation is due to "consumption smoothing," where saving and dissaving help protect Estonia from macroeconomic shocks. Estonia's significant connections to Finland, including a contemporaneous consumption correlation of 0.771, are most likely due to the aforementioned historic ties that manifest themselves through trade and financial linkages.

Lithuania shows high correlations with its neighbors, particularly for output. These, however, are somewhat lower than Estonia's, but in particular, the correlation versus the Nordic cycle (0.627), which is driven partially by Sweden (0.604), overshadows the connection to Germany (0.487). Lithuanian consumption is not synchronized with partner consumption (rather, it is most closely connected to Lithuanian output). Lithuanian investment, however, is highly synchronized with foreign GDP; after Baltic output itself, the highest contemporaneous correlation is vis-à-vis Germany (0.745), with the United States (0.649) in a strong third place.

Latvia also exhibits weaker connections than does Estonia. Latvian output consistently "leads" foreign output, although correlations between Latvian and Nordic output (0.669) and Latvian and German output (0.644) one quarter ahead are relatively strong. Linkages between Latvian and partner consumption are even weaker, except versus Russian consumption (0.509), indicating the presence of 
important links that continue to this day. Investment performs slightly better than does output, with strong links to the German (0.602) and the Nordic PC1 (DenmarkNorway) common cycle (with a coefficient of 0.654 ).

These results show that, of the three Baltic nations, Estonia is the most closely interconnected to the global economy. Lithuania shows strong ties as well that are worthy of closer inspection. Further research will be able to investigate these causes, such as Finnish investment and cultural ties in the case of Estonia, or connections between Lithuania and Latvia or between Latvia and Russia. Likewise, potential avenues for growth can be explored for Latvia, which shows the lowest degree of contemporaneous output cycle synchronization in the Baltics.

\section{DISCUSSION AND CONCLUSION}

The Nordic and Baltic regions share a long history, from the era of the Hanseatic League (which incorporated Riga in the 13th century), through the centuries of shared empire, to the present day. After the long period of Soviet rule, these historic linkages are being re-established and strengthened.

In examining this important economic space, this paper achieves two goals. First, it uses time-series methods to extract business cycles, both for individual countries and for specific regions. The paper then uses these cycles to examine interconnections through a study of business-cycle synchronization.

Overall, five key findings are uncovered. First, while the Baltic countries form a distinct economic space with common output and consumption cycles, the Nordic region is less integrated. Two consumption cycles are extracted, one based on Norway and Denmark, and the other based on Finland and Sweden. This has major implications for the future of a common Nordic-Baltic economic region.

Second, an examination of business-cycle synchronization shows that, of the three Baltic nations, Estonia exhibits the strongest connections to regional and global trading partners. Lithuania, as well, shows some degree of business-cycle synchronization with its neighbors, particularly regarding investment. Latvia, on the other hand, is often out of sync with its neighbors, except in a few key cases. As the Baltic region forges a common identity in the European Union and the world, any economic disparities might undermine common efforts at economic development. Fostering common economic policies might help the region deepen its common ties to the global economy.

Third, the interconnections between each Baltic country and the Nordic region are generally stronger than versus Germany. Key instances mentioned above include Estonian output, Lithuanian output (but not investment), and Latvian consumption. This suggests that a key hypothesis highlighted in this paper - that subregional integration overshadows EU-wide integration - is supported. This may, on the one hand, suggest limits to continent-wide integration, but on the other hand, it might encourage policymakers to treat the Baltic Sea region as a coherent whole, particularly regarding foreign investment in Lithuania and Latvia.

Fourth, key differences are highlighted among the macroeconomic variables in each Baltic country. Estonian output is highly synchronized vis-à-vis the rest of the world, but investment is not. The opposite is true for Latvia, and to a lesser extent, 
Lithuania. This has implications for growth and investment policy, for both governments and individual firms.

Finally, specific linkages are worthy of further research and investigation, particularly with regard to specific causes and drivers. The Estonian-Finnish relationship, shown here are strong output and consumption correlations, might be examined with regard to particular firms and products. Likewise, the high LatvianRussian consumption correlation is worthy of similar examination. Isolating these channels will help national and EU policymakers, as well as individual firms, foster further economic connections.

\section{REFERENCES}

Aastveit, K. A., Jore, A. S., \& Ravazzolo, F. (2016). Identification and Real-Time Forecasting of Norwegian Business Cycles. International Journal of Forecasting, 32(2), 283-292. https://doi.org/10.2139/ssrn.2616800

Artis, M. J., Fidrmuc, J. \& Scharler, J. (2008). The Transmission of Business Cycles: Implications for EMU Enlargement. Economics of Transition, 16(3), 559-582. https://doi.org/10.1111/j.1468-0351.2008.00325.x

Backus, D. K., Kehoe, P. J., \& Kydland, F. E. (1994). Dynamics of the Trade Balance and the Terms of Trade: the J-Curve? American Economic Review, 84, 84-103. https://doi.org/10.3386/w4242

Darvas, Z., \& Szapáry, G. (2008). Business Cycle Synchronization in the Enlarged EU. Open Economies Review, 19(1), 1-19. https://doi.org/10.1111/rode.12134

Di Giorgio, C. (2016). Business Cycle Synchronization of CEECs with the Euro Area: Regime Switching Approach. Journal of Common Market Studies, 54(2), 284-300. https://doi.org/10.1111/jcms.12302

Fadejeva, L. \& Melihovs, A. (2008). The Baltic States and Europe: Common Factors of Economic Activity. Baltic Journal of Economics, 8(1), 75-96. https://doi.org/10.1080/1406099x.2008.10840446

Hegerty, S. W. (2010). Central European Business Cycles: Might Global (and local) Linkages Dominate Regional Ones? Eastern European Economics, 48(2), 56-73.

Hodrick, R., \& Prescott, E. C. (1997). Postwar U.S. Business Cycles: An Empirical Investigation. Journal of Money, Credit, and Banking, 29(1), 1-16. https://doi.org/10.4324/9780203070710.pt8

International Monetary Fund. (2015). Output, consumption, investment, and price indices 1995 to 2014. Retrieved from International Financial Statistics online database.

Jiménez-Rodríguez, R., Morales-Zumaquero, A., \& Égert, B. (2013). Business Cycle Synchronization between Euro Area and Central and Eastern European Countries. Review of Development Economics, 17(2), 379395. 
Table 1. Principal Components Analysis

\begin{tabular}{|c|c|c|c|c|c|c|c|}
\hline Nordic Y & & & & Nordic C & & & \\
\hline Number & Value & Prop. & & Number & Value & Prop. & \\
\hline 1 & 2.548 & 0.637 & & 1 & 1.929 & 0.482 & \\
\hline 2 & 0.811 & 0.203 & & 2 & 1.23 & 0.308 & \\
\hline 3 & 0.432 & 0.108 & & 3 & 0.455 & 0.114 & \\
\hline 4 & 0.209 & 0.052 & & 4 & 0.386 & 0.096 & \\
\hline Eigenvec. & & & & Eigenvec. & & & \\
\hline Variable & PC 1 & & & Variable & PC 1 & PC 2 & \\
\hline Denmark & 0.501 & & & Denmark & 0.627 & -0.025 & \\
\hline Finland & 0.565 & & & Finland & -0.343 & 0.693 & \\
\hline Norway & 0.343 & & & Norway & 0.626 & 0.046 & \\
\hline Sweden & 0.558 & & & Sweden & 0.312 & 0.719 & \\
\hline Correlations & & & & Correlations & & & \\
\hline & Denm. & Finland & Norw. & & Denm. & Finland & Norw. \\
\hline Finland & 0.597 & 1 & & Finland & -0.332 & 1 & \\
\hline Norway & 0.257 & 0.407 & 1 & Norway & 0.612 & -0.29 & 1 \\
\hline Sweden & 0.629 & 0.782 & 0.31 & Sweden & 0.273 & 0.228 & 0.316 \\
\hline Baltic Y & & & & & Baltic C & & \\
\hline Number & Value & Prop. & Number & Value & Prop. & & \\
\hline 1 & 2.596 & 0.866 & 1 & 1.95 & 0.65 & & \\
\hline 2 & 0.254 & 0.085 & 2 & 0.836 & 0.279 & & \\
\hline 3 & 0.15 & 0.05 & 3 & 0.214 & 0.071 & & \\
\hline Eigenvec. & & & Eigenvec. & & & & \\
\hline Variable & PC 1 & & Variable & $\mathrm{PC} 1$ & & & \\
\hline Estonia & 0.585 & & Estonia & 0.663 & & & \\
\hline
\end{tabular}


Table 2. Cross-Correlation Functions: Baltic Country Lags $(-i)$ or Leads $(+i)$ Partner Country

\begin{tabular}{|l|r|r|r|r|r|r|r|r|r|}
\hline Estonia Y & \multicolumn{1}{c|}{-4} & \multicolumn{1}{c|}{-3} & \multicolumn{1}{c|}{-2} & \multicolumn{1}{c|}{-1} & \multicolumn{1}{c|}{0} & \multicolumn{1}{c|}{1} & \multicolumn{1}{c|}{2} & \multicolumn{1}{c|}{3} & \multicolumn{1}{c|}{} \\
\hline German Y & 0.080 & 0.253 & 0.446 & 0.641 & 0.726 & 0.684 & 0.562 & 0.354 & 0.148 \\
& $(0.115)$ & $(0.111)$ & $(0.102)$ & $(0.087)$ & $(0.077)$ & $(0.083)$ & $(0.094)$ & $(0.107)$ & $(0.114)$ \\
\hline Russian Y & 0.144 & 0.259 & 0.396 & 0.520 & 0.585 & 0.555 & 0.435 & 0.274 & 0.087 \\
& $(0.114)$ & $(0.111)$ & $(0.105)$ & $(0.097)$ & $(0.091)$ & $(0.094)$ & $(0.103)$ & $(0.11)$ & $(0.115)$ \\
\hline Nordic Y & 0.156 & 0.341 & 0.520 & 0.647 & 0.744 & 0.687 & 0.546 & 0.370 & 0.171 \\
(PC1) & $(0.114)$ & $(0.108)$ & $(0.097)$ & $(0.086)$ & $(0.075)$ & $(0.082)$ & $(0.095)$ & $(0.107)$ & $(0.114)$ \\
\hline U.S. Y & 0.180 & 0.298 & 0.429 & 0.566 & 0.666 & 0.676 & 0.610 & 0.488 & 0.356 \\
& $(0.114)$ & $(0.110)$ & $(0.103)$ & $(0.093)$ & $(0.084)$ & $(0.083)$ & $(0.090)$ & $(0.100)$ & $(0.108)$ \\
\hline Finnish Y & 0.198 & 0.363 & 0.545 & 0.689 & 0.771 & 0.693 & 0.522 & 0.308 & 0.106 \\
& $(0.113)$ & $(0.107)$ & $(0.096)$ & $(0.082)$ & $(0.072)$ & $(0.082)$ & $(0.097)$ & $(0.109)$ & $(0.115)$ \\
\hline
\end{tabular}

\begin{tabular}{|l|r|r|r|r|r|r|r|r|r|}
\hline Estonia C & \multicolumn{1}{|c|}{-4} & \multicolumn{1}{c|}{-3} & \multicolumn{1}{c|}{-2} & \multicolumn{1}{c|}{-1} & \multicolumn{1}{c|}{0} & \multicolumn{1}{c|}{1} & \multicolumn{1}{c|}{2} & \multicolumn{1}{c|}{3} & \multicolumn{1}{c|}{4} \\
\hline German C & -0.319 & -0.199 & -0.084 & 0.027 & 0.121 & 0.195 & 0.258 & 0.338 & 0.381 \\
& $(0.109)$ & $(0.112)$ & $(0.114)$ & $(0.113)$ & $(0.112)$ & $(0.111)$ & $(0.110)$ & $(0.108)$ & $(0.107)$ \\
\hline Russian C & 0.167 & 0.284 & 0.376 & 0.459 & 0.489 & 0.466 & 0.392 & 0.292 & 0.179 \\
& $(0.114)$ & $(0.110)$ & $(0.106)$ & $(0.101)$ & $(0.098)$ & $(0.100)$ & $(0.105)$ & $(0.110)$ & $(0.114)$ \\
\hline Nordic C & 0.277 & 0.383 & 0.462 & 0.526 & 0.593 & 0.608 & 0.540 & 0.451 & 0.316 \\
(PC1) & $(0.111)$ & $(0.106)$ & $(0.101)$ & $(0.096)$ & $(0.091)$ & $(0.090)$ & $(0.096)$ & $(0.102)$ & $(0.110)$ \\
\hline Nordic C & -0.329 & -0.348 & -0.341 & -0.329 & -0.300 & -0.257 & -0.167 & -0.092 & -0.054 \\
(PC2) & $(0.109)$ & $(0.108)$ & $(0.107)$ & $(0.107)$ & $(0.107)$ & $(0.109)$ & $(0.112)$ & $(0.114)$ & $(0.115)$ \\
\hline U.S. C & 0.098 & 0.222 & 0.350 & 0.458 & 0.520 & 0.537 & 0.529 & 0.512 & 0.452 \\
& $(0.115)$ & $(0.112)$ & $(0.107)$ & $(0.101)$ & $(0.096)$ & $(0.095)$ & $(0.097)$ & $(0.099)$ & $(0.103)$ \\
\hline Finnish C & 0.198 & 0.363 & 0.545 & 0.689 & 0.771 & 0.693 & 0.522 & 0.308 & 0.106 \\
& $(0.113)$ & $(0.107)$ & $(0.096)$ & $(0.082)$ & $(0.072)$ & $(0.082)$ & $(0.097)$ & $(0.109)$ & $(0.115)$ \\
\hline Est. Y & 0.301 & 0.500 & 0.670 & 0.797 & 0.863 & 0.843 & 0.740 & 0.619 & 0.475 \\
& $(0.110)$ & $(0.099)$ & $(0.085)$ & $(0.068)$ & $(0.057)$ & $(0.061)$ & $(0.077)$ & $(0.090)$ & $(0.102)$ \\
\hline
\end{tabular}

\begin{tabular}{|l|r|r|r|r|r|r|r|r|r|}
\hline Estonia I & \multicolumn{1}{c|}{-4} & \multicolumn{1}{c|}{-3} & \multicolumn{1}{c|}{-2} & \multicolumn{1}{c|}{-1} & \multicolumn{1}{c|}{0} & \multicolumn{1}{c|}{1} & \multicolumn{1}{c|}{2} & \multicolumn{1}{c|}{3} & \multicolumn{1}{c|}{4} \\
\hline Baltic Y & 0.124 & 0.126 & 0.131 & 0.127 & 0.122 & 0.113 & 0.096 & 0.076 & 0.055 \\
(PC1) & $(0.115)$ & $(0.114)$ & $(0.113)$ & $(0.112)$ & $(0.112)$ & $(0.113)$ & $(0.113)$ & $(0.114)$ & $(0.115)$ \\
\hline & 0.044 & 0.048 & 0.042 & 0.031 & 0.017 & 0.013 & 0.007 & 0.004 & -0.001 \\
German Y & $(0.115)$ & $(0.115)$ & $(0.114)$ & $(0.113)$ & $(0.112)$ & $(0.113)$ & $(0.114)$ & $(0.115)$ & $(0.115)$ \\
\hline & 0.211 & 0.187 & 0.143 & 0.103 & 0.070 & 0.066 & 0.060 & 0.053 & 0.047 \\
Russian Y & $(0.113)$ & $(0.113)$ & $(0.113)$ & $(0.113)$ & $(0.112)$ & $(0.113)$ & $(0.114)$ & $(0.115)$ & $(0.115)$ \\
\hline Nordic Y & 0.078 & 0.079 & 0.082 & 0.083 & 0.057 & 0.049 & 0.038 & 0.029 & 0.022 \\
(PC1) & $(0.115)$ & $(0.114)$ & $(0.114)$ & $(0.113)$ & $(0.112)$ & $(0.113)$ & $(0.114)$ & $(0.115)$ & $(0.115)$ \\
\hline & 0.084 & 0.107 & 0.121 & 0.125 & 0.106 & 0.095 & 0.081 & 0.063 & 0.047 \\
U.S. Y & $(0.115)$ & $(0.114)$ & $(0.113)$ & $(0.112)$ & $(0.112)$ & $(0.113)$ & $(0.114)$ & $(0.114)$ & $(0.115)$ \\
\hline & 0.072 & 0.078 & 0.074 & 0.064 & 0.052 & 0.044 & 0.034 & 0.023 & 0.012 \\
Finnish Y & $(0.115)$ & $(0.114)$ & $(0.114)$ & $(0.113)$ & $(0.112)$ & $(0.113)$ & $(0.114)$ & $(0.115)$ & $(0.115)$ \\
\hline
\end{tabular}

\begin{tabular}{|l|r|r|r|r|r|r|r|r|r|}
\hline Lith. Y & \multicolumn{1}{|c|}{-4} & \multicolumn{1}{c|}{-3} & \multicolumn{1}{c|}{-2} & -1 & 0 & 1 & 2 & \multicolumn{1}{c|}{3} & \multicolumn{1}{c|}{4} \\
\hline German Y & 0.144 & 0.224 & 0.329 & 0.427 & 0.487 & 0.452 & 0.361 & 0.257 & 0.108 \\
& $(0.114)$ & $(0.112)$ & $(0.108)$ & $(0.102)$ & $(0.098)$ & $(0.101)$ & $(0.106)$ & $(0.111)$ & $(0.115)$ \\
\hline Russian Y & 0.109 & 0.169 & 0.244 & 0.316 & 0.369 & 0.363 & 0.313 & 0.230 & 0.135 \\
& $(0.115)$ & $(0.113)$ & $(0.111)$ & $(0.107)$ & $(0.105)$ & $(0.106)$ & $(0.108)$ & $(0.112)$ & $(0.114)$ \\
\hline Nordic Y & 0.190 & 0.331 & 0.446 & 0.570 & 0.627 & 0.620 & 0.520 & 0.404 & 0.279 \\
(PC1) & $(0.113)$ & $(0.108)$ & $(0.102)$ & $(0.093)$ & $(0.088)$ & $(0.089)$ & $(0.097)$ & $(0.105)$ & $(0.111)$ \\
\hline U.S. Y & 0.228 & 0.324 & 0.453 & 0.571 & 0.650 & 0.686 & 0.634 & 0.552 & 0.461 \\
& $(0.112)$ & $(0.109)$ & $(0.102)$ & $(0.093)$ & $(0.085)$ & $(0.082)$ & $(0.088)$ & $(0.096)$ & $(0.102)$ \\
\hline Swedish & 0.062 & 0.147 & 0.245 & 0.409 & 0.604 & 0.549 & 0.521 & 0.506 & 0.398 \\
Y & $(0.115)$ & $(0.113)$ & $(0.110)$ & $(0.103)$ & $(0.090)$ & $(0.095)$ & $(0.097)$ & $(0.099)$ & $(0.106)$ \\
\hline
\end{tabular}




\begin{tabular}{|l|r|r|r|r|r|r|r|r|r|}
\hline Lith. C & -4 & -3 & -2 & -1 & 0 & 1 & 2 & 3 & 4 \\
\hline German C & -0.030 & -0.064 & -0.069 & -0.079 & -0.091 & -0.138 & -0.245 & -0.259 & -0.101 \\
& $(0.115)$ & $(0.114)$ & $(0.114)$ & $(0.113)$ & $(0.112)$ & $(0.112)$ & $(0.110)$ & $(0.111)$ & $(0.115)$ \\
\hline Russian C & -0.147 & -0.25 & -0.113 & -0.017 & 0.072 & 0.353 & 0.435 & 0.476 & 0.544 \\
& $(0.114)$ & $(0.111)$ & $(0.113)$ & $(0.113)$ & $(0.112)$ & $(0.106)$ & $(0.103)$ & $(0.101)$ & $(0.097)$ \\
\hline Nordic C & 0.272 & 0.190 & 0.190 & 0.341 & 0.284 & 0.406 & 0.425 & 0.383 & 0.456 \\
(PC1) & $(0.111)$ & $(0.113)$ & $(0.112)$ & $(0.106)$ & $(0.108)$ & $(0.103)$ & $(0.103)$ & $(0.106)$ & $(0.103)$ \\
\hline Nordic & 0.182 & 0.078 & -0.115 & -0.195 & -0.242 & -0.365 & -0.355 & -0.253 & -0.274 \\
C (PC2) & $(0.114)$ & $(0.114)$ & $(0.113)$ & $(0.111)$ & $(0.109)$ & $(0.105)$ & $(0.107)$ & $(0.111)$ & $(0.111)$ \\
\hline U.S. C & 0.184 & 0.128 & 0.118 & 0.155 & 0.122 & 0.131 & 0.183 & 0.170 & 0.181 \\
& $(0.114)$ & $(0.114)$ & $(0.113)$ & $(0.112)$ & $(0.112)$ & $(0.112)$ & $(0.112)$ & $(0.113)$ & $(0.114)$ \\
\hline Lith. Y & 0.062 & 0.147 & 0.245 & 0.409 & 0.604 & 0.549 & 0.521 & 0.506 & 0.398 \\
& $(0.112)$ & $(0.111)$ & $(0.109)$ & $(0.103)$ & $(0.090)$ & $(0.094)$ & $(0.096)$ & $(0.097)$ & $(0.103)$ \\
\hline
\end{tabular}

\begin{tabular}{|l|r|r|r|r|r|r|r|r|r|}
\hline Lith. I. & \multicolumn{1}{|c|}{-4} & \multicolumn{1}{c|}{-3} & \multicolumn{1}{c|}{-2} & \multicolumn{1}{c|}{-1} & \multicolumn{1}{c|}{0} & \multicolumn{1}{c|}{1} & \multicolumn{1}{c|}{2} & \multicolumn{1}{c|}{3} & \multicolumn{1}{c|}{4} \\
\hline Baltic Y & 0.410 & 0.577 & 0.719 & 0.797 & 0.799 & 0.664 & 0.495 & 0.296 & 0.113 \\
(PC1) & $(0.105)$ & $(0.094)$ & $(0.079)$ & $(0.068)$ & $(0.068)$ & $(0.085)$ & $(0.099)$ & $(0.110)$ & $(0.115)$ \\
\hline & 0.368 & 0.502 & 0.593 & 0.704 & 0.745 & 0.588 & 0.432 & 0.271 & 0.089 \\
German Y & $(0.107)$ & $(0.099)$ & $(0.092)$ & $(0.08)$ & $(0.075)$ & $(0.092)$ & $(0.103)$ & $(0.110)$ & $(0.115)$ \\
\hline & 0.147 & 0.261 & 0.357 & 0.417 & 0.457 & 0.363 & 0.156 & -0.016 & -0.167 \\
Russian Y & $(0.114)$ & $(0.111)$ & $(0.106)$ & $(0.103)$ & $(0.100)$ & $(0.105)$ & $(0.113)$ & $(0.115)$ & $(0.114)$ \\
\hline Nordic Y & 0.502 & 0.593 & 0.704 & 0.745 & 0.588 & 0.432 & 0.271 & 0.089 & 0.000 \\
(PC1) & $(0.100)$ & $(0.092)$ & $(0.081)$ & $(0.076)$ & $(0.091)$ & $(0.102)$ & $(0.110)$ & $(0.114)$ & $(0.115)$ \\
\hline & 0.207 & 0.329 & 0.486 & 0.603 & 0.649 & 0.599 & 0.450 & 0.265 & 0.125 \\
U.S. Y & $(0.113)$ & $(0.108)$ & $(0.100)$ & $(0.09)$ & $(0.086)$ & $(0.091)$ & $(0.102)$ & $(0.111)$ & $(0.115)$ \\
\hline
\end{tabular}

\begin{tabular}{|l|r|r|r|r|r|r|r|r|r|}
\hline Latvia $Y$ & \multicolumn{1}{c|}{-4} & \multicolumn{1}{c|}{-3} & \multicolumn{1}{c|}{-2} & -1 & 0 & 1 & 2 & \multicolumn{1}{c|}{3} & \multicolumn{1}{c|}{4} \\
\hline German Y & 0.020 & 0.202 & 0.380 & 0.513 & 0.601 & 0.644 & 0.595 & 0.457 & 0.309 \\
& $(0.115)$ & $(0.112)$ & $(0.105)$ & $(0.097)$ & $(0.090)$ & $(0.087)$ & $(0.092)$ & $(0.102)$ & $(0.110)$ \\
\hline Russian Y & 0.14 & 0.255 & 0.405 & 0.519 & 0.555 & 0.557 & 0.485 & 0.367 & 0.192 \\
& $0(0.114)$ & $(0.111)$ & $(0.104)$ & $(0.097)$ & $(0.094)$ & $(0.094)$ & $(0.100)$ & $(0.107)$ & $(0.113)$ \\
\hline Nordic Y & 0.061 & 0.256 & 0.442 & 0.557 & 0.669 & 0.684 & 0.634 & 0.504 & 0.379 \\
(PC1) & $(0.115)$ & $(0.111)$ & $(0.102)$ & $(0.094)$ & $(0.084)$ & $(0.083)$ & $(0.088)$ & $(0.099)$ & $(0.107)$ \\
\hline U.S. Y & 0.129 & 0.279 & 0.415 & 0.556 & 0.624 & 0.689 & 0.687 & 0.630 & 0.542 \\
& $(0.115)$ & $(0.110)$ & $(0.104)$ & $(0.094)$ & $(0.088)$ & $(0.082)$ & $(0.083)$ & $(0.089)$ & $(0.097)$ \\
\hline Swed. Y & -0.191 & 0.001 & 0.206 & 0.397 & 0.551 & 0.601 & 0.601 & 0.549 & 0.459 \\
& $(0.113)$ & $(0.115)$ & $(0.112)$ & $(0.104)$ & $(0.094)$ & $(0.090)$ & $(0.091)$ & $(0.096)$ & $(0.103)$ \\
\hline
\end{tabular}

\begin{tabular}{|l|r|r|r|r|r|r|r|r|r|}
\hline Latvia C & \multicolumn{1}{|c|}{-4} & \multicolumn{1}{|c|}{-3} & \multicolumn{1}{c|}{-2} & -1 & \multicolumn{1}{c|}{0} & \multicolumn{1}{c|}{1} & \multicolumn{1}{c|}{2} & \multicolumn{1}{c|}{3} & \multicolumn{1}{c|}{4} \\
\hline German & -0.147 & -0.072 & 0.019 & 0.077 & 0.198 & 0.188 & 0.332 & 0.369 & 0.281 \\
$\mathrm{C}$ & $(0.114)$ & $(0.114)$ & $(0.114)$ & $(0.113)$ & $(0.110)$ & $(0.111)$ & $(0.107)$ & $(0.107)$ & $(0.111)$ \\
\hline Russian & 0.149 & 0.369 & 0.438 & 0.478 & 0.509 & 0.403 & 0.322 & 0.219 & 0.120 \\
$\mathrm{C}$ & $(0.114)$ & $(0.107)$ & $(0.102)$ & $(0.099)$ & $(0.097)$ & $(0.104)$ & $(0.108)$ & $(0.112)$ & $(0.115)$ \\
\hline Nordic C & 0.162 & 0.280 & 0.263 & 0.394 & 0.468 & 0.532 & 0.500 & 0.479 & 0.394 \\
(PC1) & $(0.114)$ & $(0.110)$ & $(0.110)$ & $(0.104)$ & $(0.099)$ & $(0.096)$ & $(0.099)$ & $(0.101)$ & $(0.106)$ \\
\hline Nordic C & -0.210 & -0.187 & -0.160 & -0.128 & -0.114 & -0.075 & -0.025 & -0.027 & 0.009 \\
(PC2) & $(0.113)$ & $(0.113)$ & $(0.113)$ & $(0.112)$ & $(0.112)$ & $(0.113)$ & $(0.114)$ & $(0.115)$ & $(0.115)$ \\
\hline U.S. C & 0.053 & 0.197 & 0.330 & 0.415 & 0.477 & 0.555 & 0.545 & 0.538 & 0.483 \\
& $(0.112)$ & $(0.110)$ & $(0.106)$ & $(0.102)$ & $(0.099)$ & $(0.094)$ & $(0.094)$ & $(0.095)$ & $(0.098)$ \\
\hline Swed. C & -0.170 & -0.140 & -0.107 & -0.027 & 0.015 & 0.072 & 0.154 & 0.173 & 0.203 \\
& $(0.114)$ & $(0.114)$ & $(0.113)$ & $(0.113)$ & $(0.112)$ & $(0.113)$ & $(0.113)$ & $(0.113)$ & $(0.113)$ \\
\hline Latvia Y & 0.381 & 0.546 & 0.651 & 0.708 & 0.747 & 0.712 & 0.625 & 0.506 & 0.380 \\
& $(0.107)$ & $(0.096)$ & $(0.086)$ & $(0.080)$ & $(0.075)$ & $(0.08)$ & $(0.089)$ & $(0.099)$ & $(0.107)$ \\
\hline
\end{tabular}




\begin{tabular}{|l|r|r|r|r|r|r|r|r|r|}
\hline Latvia I & \multicolumn{1}{|c|}{-4} & \multicolumn{1}{c|}{-3} & \multicolumn{1}{c|}{-2} & -1 & 0 & 1 & 2 & \multicolumn{1}{c|}{3} & 4 \\
\hline Baltic Y & 0.357 & 0.494 & 0.652 & 0.762 & 0.831 & 0.797 & 0.705 & 0.583 & 0.370 \\
(PC1) & $(0.108)$ & $(0.100)$ & $(0.086)$ & $(0.073)$ & $(0.063)$ & $(0.068)$ & $(0.081)$ & $(0.093)$ & $(0.107)$ \\
\hline Ger. Y & -0.025 & 0.142 & 0.335 & 0.457 & 0.602 & 0.590 & 0.536 & 0.425 & 0.273 \\
& $(0.115)$ & $(0.114)$ & $(0.107)$ & $(0.101)$ & $(0.090)$ & $(0.091)$ & $(0.096)$ & $(0.104)$ & $(0.111)$ \\
\hline Russ. Y & 0.127 & 0.207 & 0.309 & 0.429 & 0.430 & 0.458 & 0.401 & 0.297 & 0.184 \\
& $(0.115)$ & $(0.112)$ & $(0.108)$ & $(0.102)$ & $(0.102)$ & $(0.101)$ & $(0.104)$ & $(0.110)$ & $(0.114)$ \\
\hline Nordic Y & 0.060 & 0.244 & 0.407 & 0.471 & 0.654 & 0.609 & 0.535 & 0.438 & 0.281 \\
(PC1) & $(0.115)$ & $(0.111)$ & $(0.104)$ & $(0.100)$ & $(0.085)$ & $(0.090)$ & $(0.096)$ & $(0.103)$ & $(0.111)$ \\
\hline U.S. Y & 0.121 & 0.253 & 0.369 & 0.490 & 0.579 & 0.581 & 0.551 & 0.474 & 0.423 \\
& $(0.115)$ & $(0.111)$ & $(0.106)$ & $(0.099)$ & $(0.092)$ & $(0.092)$ & $(0.095)$ & $(0.101)$ & $(0.105)$ \\
\hline Swed. Y & -0.092 & 0.036 & 0.189 & 0.318 & 0.494 & 0.533 & 0.526 & 0.521 & 0.391 \\
& $(0.115)$ & $(0.115)$ & $(0.112)$ & $(0.107)$ & $(0.098)$ & $(0.096)$ & $(0.097)$ & $(0.098)$ & $(0.106)$ \\
\hline
\end{tabular}

$Y=$ output, $C=$ consumption, $I=$ investment. Standard errors in parentheses. Italic $=$ highest (absolute) value for a specific pair.

\section{AUTHOR'S SHORT BIOGRAPHY}

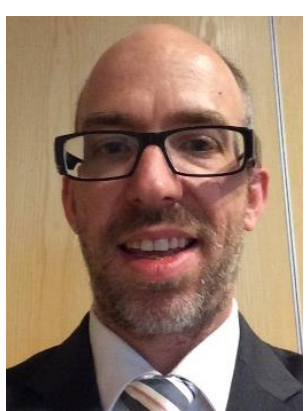

Scott W. Hegerty is an Associate Professor at Northeastern Illinois University in Chicago. He has previously taught at Canisius College and Beloit College, and worked as a Research Associate at the University of Wisconsin-Milwaukee (UWM). He received the Bachelor of Science in history from the University of Wisconsin-Eau Claire in 1999, the M.A. in economics from UWM in 2004, and the Ph.D. in economics from UWM in 2007. His research interests include macroeconomic integration and connections among foreign exchange markets, particularly in Northern and Central Europe, as well as urban geography and regional analysis both in the United States and in formerly planned cities in Europe. 